\title{
rhTSH-aided radioiodine ablation and treatment of differentiated thyroid carcinoma: a comprehensive review
}

\author{
Markus Luster ${ }^{1}$, Francesco Lippi ${ }^{2}$, Barbara Jarzab ${ }^{3}$, Petros Perros ${ }^{4}$, \\ Michael Lassmann ${ }^{1}$, Christoph Reiners ${ }^{1}$ and Furio Pacini ${ }^{5}$
}

\author{
${ }^{1}$ Department of Nuclear Medicine, University of Würzburg, Josef-Schneider-Str.2,97080 Würzburg, Germany \\ ${ }^{2}$ Department of Endocrinology and Metabolism, Section of Endocrinology, University of Pisa, Via Paradisa, 2,56124 Pisa, Italy \\ ${ }^{3}$ Department of Nuclear Medicine and Endocrine Oncology, Maria Sklodowska-Curie Memorial Institute and Centre of Oncology, \\ Gliwice Branch, Wybrzeze Armil Krajowej, 44-100 Gliwice, Poland \\ ${ }^{4}$ Department of Endocrinology, Freeman Hospital, Freeman Road, High Heaton, Newcastle upon Tyne NE7 7DN, UK \\ ${ }^{5}$ Department of Internal Medicine, Endocrinology, Metabolism and Biochemistry, Section of Endocrinology and Metabolism, \\ University of Siena, Via Bracci, 53100 Siena, Italy
}

(Requests for offprints should be addressed to M Luster; Email: luster@nuklearmedizin.uni-wuerzburg.de)

\begin{abstract}
Traditionally, withdrawal of thyroid hormone has been used to attain the increase in serum TSH concentrations that are believed to optimize the trapping and retention of radioiodine for diagnostic procedures, thyroid remnant ablation and treatment of patients with differentiated thyroid cancer (DTC). However, withdrawal frequently causes clinical hypothyroidism, with resultant cognitive impairment, emotional dysfunction, physical discomfort, health risks in patients who are elderly, frail or have concomitant illness, and impaired quality of life and ability to work. Recombinant human TSH (rhTSH) was developed to provide TSH stimulation without withdrawal of thyroid hormone and the associated morbidity. rhTSH has been approved as an adjunct for diagnostic procedures in patients with DTC, but is currently an experimental aid in thyroid remnant ablation and the treatment of thyroid tumours.

In the period 1997-2004, nearly 30 medical centres worldwide have reported on almost 400 patients with DTC who were given rhTSH in preparation for radioiodine ablation of thyroid remnants or treatment of local tumours of metastatic disease. We have analysed and summarized the findings reported in this literature. Ablation aided by the standard course of rhTSH, two consecutive daily injections of $0.9 \mathrm{mg}$, had success rates better than $84 \%$ in 90 patients given radioiodine activities in excess of $4000 \mathrm{MBq}$. However, when $1110 \mathrm{MBq}$ was administered, success rates were $81.2 \%$ in 16 patients given the standard course of rhTSH and 4-day withdrawal of thyroid hormone around the time of radioiodine administration in one study, but $54 \%$ in 70 patients in another study. rhTSH-aided treatment of persistent or recurrent local or metastatic cancer, or both, with from one to six courses of radioiodine $1000-19055 \mathrm{MBq}$, achieved $2 \%$ complete remission, $36 \%$ partial response and $27 \%$ disease stabilization rates, for a $65 \%$ clinical benefit rate, in 115 primarily elderly, late-stage patients for whom responses were reported. Twelve of these patients died as a result of progressive disease or were discharged from hospital into hospice care.

Generally, rhTSH was very well tolerated. However, in a minority of patients with central nervous system, spinal or bone metastases, or bulky thyroid remnant or neck lesions with or without poor pulmonary reserve, administration of $\mathrm{rhTSH}$, like thyroid hormone withdrawal, was found to stimulate expansion of the tumour, with ensuing compression of key anatomical structures and neurological, respiratory or other clinical complications. The rapid onset, response to glucocorticoids and radiological findings of peritumoural oedema or, less commonly, haemorrhage in the published cases, strongly suggest that the tumour expansion was the result of swelling rather than growth. As in the case of thyroid hormone withdrawal, special attention and glucocorticoid premedication are thus warranted when rhTSH is given to patients known or suspected to have the above characteristics.
\end{abstract}


Dosimetric data suggest that whole-body and whole-blood radioiodine clearance may be faster in euthyroid patients after administration of rhTSH. In theory, the faster clearance could allow, or demand, increased radioiodine activities when rhTSH is used, but clinical data to date suggest that this may be unnecessary. The faster clearance also might result in safety or convenience benefits with the use of rhTSH, such as decreased exposure of extrathyroid areas to radiation, and shorter hospital stays.

In conclusion, in preliminary results from open-label studies, both rhTSH-aided tumour ablation and treatment have been well tolerated and have shown efficacy in substantial proportions of patients. rhTSH-aided ablation merits further study. rhTSH-aided treatment may be preferred in patients who are at greater risk of hypothyroid complications from withdrawal of thyroid hormone or are unable to produce sufficient endogenous TSH, and warrants additional investigation in younger patients at earlier stages of thyroid cancer.

Endocrine-Related Cancer (2005) 12 49-64

\section{Introduction}

For more than five decades, along with surgical resection and thyroid hormone suppressive therapy (THST) with levothyroxine $\left(\mathrm{LT}_{4}\right)$, treatment with iodine-131 $\left({ }^{131} \mathrm{I}\right)$ has been a mainstay in the management of differentiated thyroid carcinoma (DTC) (Reiners \& Farahati 1999, Schlumberger \& Pacini 2003). ${ }^{131}$ I activities of at least $925 \mathrm{MBq}$ are administered for two main purposes: ablation of healthy thyroid tissue remaining after thyroidectomy and of any microscopic cancer deposits, or curative or palliative treatment of inoperable functioning tumour. Administration of such radioiodine activities also permits 'post-therapy' whole-body scanning (WBS), which may detect lesions not visualized on diagnostic WBS (dxWBS) or other imaging modalities, and thereby may influence disease management (Schlumberger \& Pacini 2003).

The trapping and retention of radioiodine by functioning thyroid tissue are believed to be optimized when serum concentrations of thyroid-stimulating hormone (TSH) are high $(30-50 \mu \mathrm{IU} / \mathrm{ml}$ or more; McDougall \& Weigel 2001). Historically, increased serum TSH has been achieved by the withdrawal of $\mathrm{LT}_{4}$ for 4 weeks or more. However, during and often beyond this time, withdrawal of THST frequently results in clinical hypothyroidism. Symptoms including cognitive impairment, emotional dysfunction and physical discomfort may significantly disrupt patients' lives, especially as a large proportion of patients are young or middle-aged, in good general health and therefore more active (Dow et al. 1997, Mazzaferri \& Kloos 2000, Brans et al. 2001, M Luster, R Felbinger, M Dietlen \& C Reiners, unpublished observation). In the elderly, muscle weakness and cerebellar ataxia as a result of hypothyroidism can impair ambulation, increasing the risk of trauma (Brans et al. 2001).
Withdrawal of THST also may pose a danger of cardiac, cerebrovascular, pulmonary or neurological complications, especially in patients with co-existing disorders or metastatic involvement of these organ systems, or in frail or elderly individuals. A documented potential risk of withdrawal of THST for all patients is stimulation of cancer progression in tumours generally exposed to increased TSH concentrations for several weeks, both during the withdrawal of $\mathrm{LT}_{4}$ and while $\mathrm{TSH}$ concentrations return to baseline after the resumption of THST (Rudavsky \& Freeman 1998, Vargas et al. 1999, Jarzab et al. 2000a, Robbins et al. 2001). Indeed, contraindication to the withdrawal of THST because of risks of tumour complications or progression has precluded the use of radioiodine therapy in some patients with greatest need for such treatment (Berg et al. 2002). As a general rule, the actual or potential consequences of hypothyroidism render the majority of patients with DTC unwilling or unable to undergo more than one withdrawal of THST per year (Mazzaferri \& Kloos 2000).

In addition, withdrawal is not always effective. Even after weeks of withdrawal, TSH concentrations may not increase sufficiently in cases of persistent thyroid hormone production by large thyroid remnants or functionally active metastases, of hypothalamic or pituitary dysfunction, of long-term steroid administration as prophylaxis against tumour compression of key anatomical structures, or of unusually slow response, particularly in the elderly (Adler et al. 1998, Perros 1999, Luster et al. 2000a, Jarzab et al. 2003). Exogenous stimulation with bovine TSH was introduced as an alternative to withdrawal of THST, but because of frequent adverse reactions and the development of neutralizing antibodies, has fallen into disuse (Schlumberger \& Pacini 2003).

Recombinant human TSH (rhTSH; Thyrogen, Genzyme Therapeutics, Cambridge, MA, USA) was 
developed to provide TSH stimulation without the requirement for THST withdrawal and the resultant metabolic disturbance, and without the drawbacks associated with the use of bovine TSH. Three clinical studies have demonstrated the safety and efficacy of rhTSH in stimulating uptake of diagnostic activities $(\leq 163 \mathrm{MBq})$ of ${ }^{131} \mathrm{I}$ and the release of thyroglobulin by thyroid remnant tissue and metastatic lesions of DTC (Meier et al. 1994, Ladenson et al. 1997, Haugen et al. 1999). As a result, rhTSH gained regulatory approval as a diagnostic adjunct in North America and Europe.

rhTSH is not licensed as an adjunct to radioiodine remnant ablation or treatment. However, since 1995, it has been administered for these purposes, to several hundred patients around the world (Schlumberger et al. 2000). Much therapeutic administration has taken place within the manufacturer's compassionate use programme, in patients likely to develop life-threatening conditions or unable to generate sufficient endogenous TSH under THST withdrawal, for whom other treatments are unavailable. However, some administration also has taken place 'off-label' in everyday practice (Adler et al. 1998, Mariani et al. 2000, Robbins et al. 2002).

By the end of August 2004, open-label experience with rhTSH-aided ablation or treatment involving a total of 394 patients had been published by some 29 medical centres worldwide (Chiu et al. 1997, Adler et al. 1998, Rudavsky \& Freeman 1998, Colleran \& Burge 1999, Perros 1999, Masiukiewicz et al. 1999, Vargas et al. 1999, Jarzab et al. 2000a,b, 2003, Lippi et al. 2000, Luster et al. 2000a,b, Mariani et al. 2000, Mazzaferri \& Kloos 2000, Robbins et al. 2000, 2001, 2002, Rotman-Pikielny et al. 2000, Aslam \& Daly 2001, Checrallah et al. 2001, McDougall \& Weigel 2001, Pellegritti et al. 2001, Berg et al. 2002, Müller et al. 2002, Pacini et al. 2002, Robeson et al. 2002, Barbaro et al. 2003, Goffman et al. 2003, Gómez Camarero et al. 2003, de Keizer et al. 2003, Menzel et al. 2003, Driedger \& Kotowycz 2004, Kovatcheva et al. 2004, Taieb et al. 2004). All but two of these studies (Pacini et al. 2002, Barbaro et al. 2003) have utilized the rhTSH regimen most investigated and now approved in the diagnostic setting: one intramuscular injection of $0.9 \mathrm{mg}$ on each of two consecutive days given during THST, with administration of ${ }^{131} \mathrm{I}$ on the third day. The published population included numerous individuals who were elderly, frail or both. Indeed, rhTSH permitted radioiodine therapy in a number of patients in whom such treatment would otherwise not have been feasible (Reiners \& Farahati 1999, Berg et al. 2002). Most publications reported a short follow-up of only 3-6 months, but in some reports the follow-up extended to several years.

Here, we provide a comprehensive review of this published experience. Throughout the text, 'ablation' refers to treatment with the primary goal of destroying thyroid remnants, and 'treatment' refers to therapy with the primary goal of destroying thyroid tumour.

\section{rhTSH-aided thyroid remnant ablation}

Currently, radioiodine ablation is widely used after thyroidectomy in patients with DTC. Four main reasons explain the popularity of the technique: (1) some studies have shown it to reduce disease recurrence and mortality rates (DeGroot et al. 1994, Mazzaferri 1997); (2) it enables sensitive 'post-therapy' WBS and, by removing healthy thyroid tissue, which is more iodine-avid than cancerous thyroid tissue, increases the sensitivity of subsequent dxWBS and measurements of thyroglobulin; (3) it is therefore perceived to confer 'peace of mind'; (4) generally, it is safe (Robbins et al. 2001, Schlumberger \& Pacini 2003).

Ablation is the standard of care in patients with 'high-risk' factors such as: age $<16$ or $>45$ years; papillary tall-cell, columnar cell or diffuse sclerosing, follicular widely invasive or poorly-differentiated histology; tumour size $>1.0-1.5 \mathrm{~cm}$ in diameter or extension beyond the thyroid capsule; large, multiple or bilateral lymph node metastases; distant metastases; increased serum thyroglobulin concentrations more than 3 months after thyroidectomy (Schlumberger \& Pacini 2003). Conversely, the consensus is that the procedure should not be applied to patients with papillary thyroid cancer stage $\mathrm{pT}_{1} \mathrm{~N}_{0} \mathrm{M}_{0}$ (tumour diameter $\leq 1 \mathrm{~cm}$ ), with unmistakable medullary or anaplastic histology, or to those who, after administration of an ${ }^{131}$ I test activity, lack thyroid bed uptake or have uptake indicating a remnant large enough to warrant further surgery (Reiners \& Farahati 1999). Disagreement exists as to the use of radioiodine ablation in other patients.

Disagreement also exists regarding the optimal ${ }^{131} \mathrm{I}$ activities for ablation. Nonetheless, activities between 1110 and $3700 \mathrm{MBq}$ commonly are used, in an attempt to deliver doses of at least $300 \mathrm{~Gy}$ to the remnant (Maxon et al. 1992, Reiners \& Farahati 1999, Robbins et al. 2001, Schlumberger \& Pacini 2003).

A major drawback to ablation has been the need for withdrawal of THST and consequent hypothyroidism (Robbins et al. 2001). Most candidates for ablation comprise the healthiest thyroid cancer patients, for whom hypothyroid morbidity is most disruptive. 
Moreover, patients are forced to wait 3-6 weeks after surgery before endogenous TSH concentrations are sufficiently increased to allow ablation to be performed. In contrast, the procedure can take place a few days after surgery when rhTSH is administered, allowing patients to move on with their lives (Reiners \& Farahati 1999, Schlumberger \& Pacini 2003). Use of rhTSH to aid radioablation, then, would appear potentially to provide patients with important advantages in safety, comfort and convenience.

In published experience to date, rhTSH-aided ablation has shown efficacy in a majority of cases with administered radioiodine activities of $1110 \mathrm{MBq}$ were used, and especially when radioiodine activities $\geq 4000 \mathrm{MBq}$ were used. The findings of these studies show the feasibility of rhTSH-aided ablation, but additional investigation is needed to optimize the procedures, and publication is awaited of the results of a randomized trial that compared the efficacy of this approach with that of withdrawal-aided ablation.

A total of 180 patients (124 women and 56 men; 163 with papillary, 9 with follicular, 1 with poorly differentiated and 7 with unreported histology; reported ages 17-77 years) have been reported to have received rhTSH-aided ablation (Table 1), 138 while receiving THST (Robbins et al. 2001, 2002, Berg et al. 2002, Pacini et al. 2002, Barbaro et al. 2003, Kovatcheva et al. 2004) and 42 in combination with conventional thyroid hormone withdrawal (Pacini et al. 2002). Three of these patients received radioiodine both for remnant ablation and treatment of metastases (Kovatcheva et al. 2004). Reported individual ${ }^{131} \mathrm{I}$ activities ranged from 740 to $9250 \mathrm{MBq}$.

Just over $60 \%$ of this population were included in a prospective study at the University of Pisa, in which patients were consecutively assigned to three groups, given THST withdrawal (50 evaluable patients), withdrawal+rhTSH (42 evaluable patients) or rhTSH alone (70 evaluable patients) (Pacini et al. 2002). All patients received tracer activities of radioiodine, $1.85 \mathrm{MBq}$, to measure 24-hour thyroid bed uptake at baseline, and the two rhTSH groups also received this tracer activity to measure the uptake $24 \mathrm{~h}$ after the last injection of rhTSH. As a result, patients in the rhTSH and withdrawal + rhTSH groups received the ablative activity of $1110 \mathrm{MBq}$ (the institutional standard), $48 \mathrm{~h}$ or $72 \mathrm{~h}$ respectively after the last injection of $\mathrm{rhTSH}$, instead of after the $24 \mathrm{~h}$ used in other studies of rhTSH-aided therapy. Thus the euthyroid patients received the ablative activity well after serum TSH concentrations had 'peaked' and when these concentrations were declining rapidly. Success of ablation was measured 6-10 months later via a withdrawal-aided
$\mathrm{dxWBS}$ performed $72 \mathrm{~h}$ after the administration of radioiodine (163 MBq).

When absence of visible thyroid bed uptake on the $\mathrm{dxWBS}$ was used as the criterion for successful ablation, the ablation rates were $84 \%$ for the THST withdrawal group and $79 \%$ for the THST withdrawal+rhTSH group, compared with $54 \%$ for the rhTSH group, a difference that was significant $(P<0.0001$ and $P<0.01$ respectively, rhTSH group compared with the withdrawal or withdrawal + rhTSH group). Of interest, if successful ablation was defined as negative thyroid bed uptake or undetectable serum thyroglobulin, the success rates would have been $88 \%$ in the THST withdrawal group, $95 \%$ in the THST withdrawal+rhTSH group and $74 \%$ in the rhTSH group.

The 24-hour delay in the administration of radioiodine may help to explain the lower ablation rate for the rhTSH group in the Pisa study. In addition, in light of the more rapid excretion of radioiodine that has been documented in the euthyroid compared with the hypothyroid state (Park et al. 1996, Haugen et al. 1999), the Pisa investigators suggested increasing the radioiodine activity as one potential means of improving the ablation rate in euthyroid patients.

Indeed, a report of rhTSH-aided ablation with mean activities of at least $4 \mathrm{GBq}$ in euthyroid patients demonstrated a much greater success rate. This retrospective review of 87 patients who underwent thyroid tumour ablation in everyday practice at Memorial-Sloan Kettering Cancer Center, New York, NY, USA in 1999 or 2000 showed an 84\% complete ablation rate in 45 euthyroid patients given rhTSH, compared with an $81 \%$ rate in 42 patients hypothyroid after withdrawal of THST (Robbins et al. 2002). In that study, successful ablation was defined as lack of visible radioiodine uptake in the thyroid bed on dxWBS, which was performed a mean $10.8 \pm 3.2$ and $11.2 \pm 2.5$ months after ablation respectively in the rhTSH and withdrawal groups. The follow-up WBS was performed with rhTSH stimulation in all patients in both groups, except five in the hypothyroid group, in whom the follow-up scan was performed after the withdrawal of THST. This difference appears not to have affected results, however, as only one of these five patients was found to have incomplete ablation. All patients in whom ablation was incomplete in the rhTSH group, and seven of eight in the withdrawal group, were found to have a partial response, defined as some visible radioiodine uptake in the thyroid bed, but 24-hour uptake in that region was less than $50 \%$ of that at baseline. At follow-up, $77 \%$ of the patients given $\operatorname{rhTSH}(n=44)$ and $64 \%$ of those in whom 


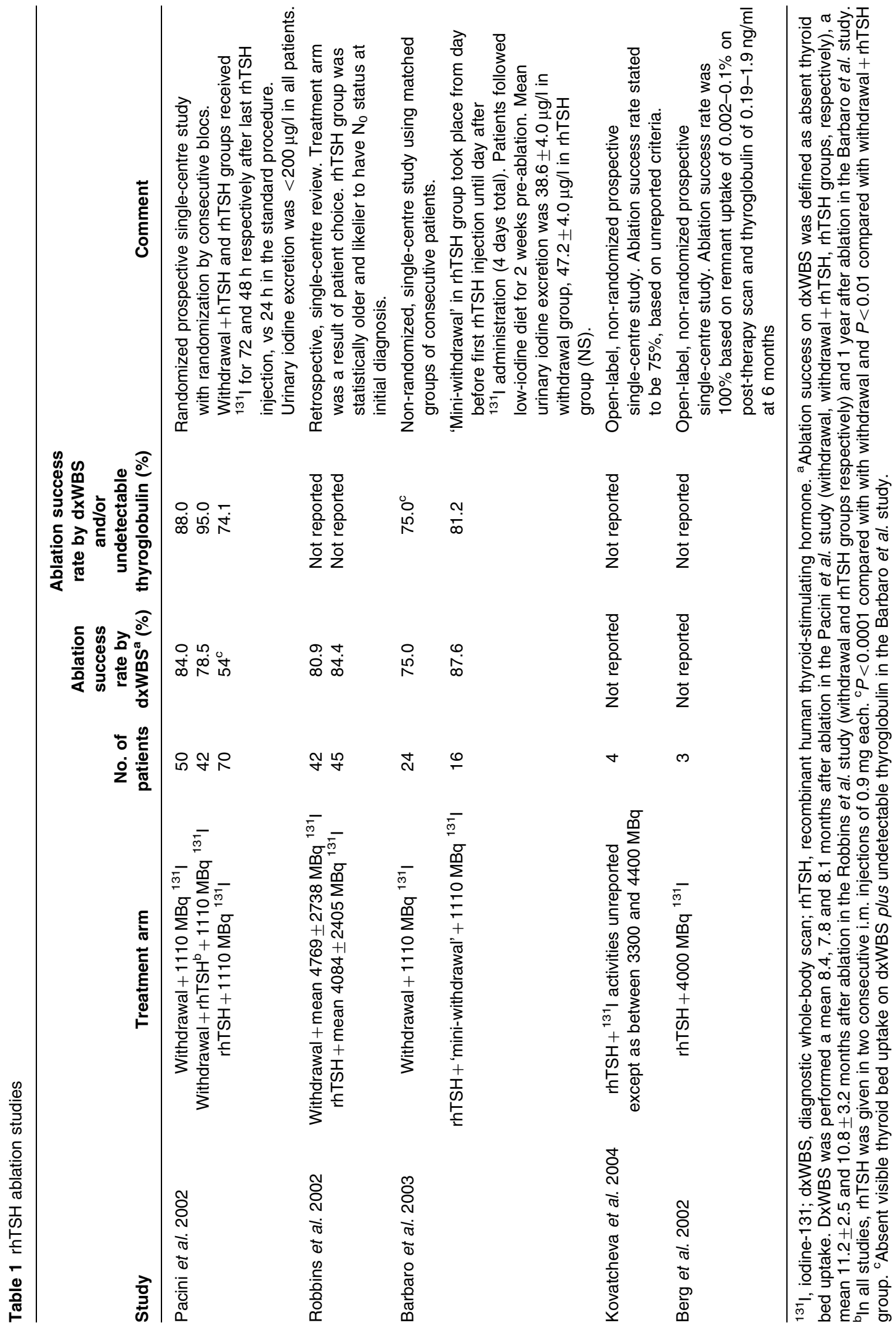


THST was withdrawn exhibited stimulated serum thyroglobulin $\leq 2 \mathrm{ng} / \mathrm{ml}$, the institutional cut-off value on an immunoradiometric assay with a functional sensitivity of $0.3 \mathrm{ng} / \mathrm{ml}$. Some $9 \%$ of those in the rhTSH group and $17 \%$ of the withdrawal group had been found to have metastatic disease on postablation WBS.

The patients of the Memorial Sloan-Kettering Cancer Center underwent dosimetric assessments with a diagnostic activity of $37-185 \mathrm{MBq}$ during the week before ablation, and the rhTSH group received significantly greater mean diagnostic activities $(90.7 \pm 62.9 \mathrm{MBq})$ than did the withdrawal group $(72.2 \pm 92.5 \mathrm{MBq}, P=0.01, t$-test). The rhTSH group underwent tumour ablation with a lower mean activity $(4085 \pm 2405 \mathrm{MBq})$ than was given to the withdrawal group $(4769 \pm 2738 \mathrm{MBq})$, but this difference was not significant. The authors noted that theirs was a retrospective analysis of groups selected by patient choice, not a prospective study, but believed that their findings supported the design of a randomized trial comparing success rates of rhTSH-stimulated and withdrawal-stimulated ablation techniques.

A recent Italian study using an ablative activity of $1110 \mathrm{MBq}$ compared two similar groups of consecutively enrolled patients: 16 received the standard rhTSH regimen but discontinued $\mathrm{LT}_{4}$ from the day before the first rhTSH injection until the day after radioiodine administration (4 days), and 24 underwent conventional withdrawal of THST (Barbaro et al. 2003). The rationale for the brief withdrawal of $\mathrm{LT}_{4}$ in the rhTSH group was that it had the potential to decrease interference with ${ }^{131}$ I uptake by the stable iodine in the thyroid hormone, the subject of earlier speculation (de Keizer et al. 2003, Löffler et al. 2003). Mean urinary iodine, measured with high-pressure liquid chromatography combined with electrochemical detection in overnight urine collected between the last rhTSH injection and the time of administration of ${ }^{131} \mathrm{I}$, was $47.2 \pm 4.0 \mu \mathrm{g} / \mathrm{l}$ in the $\mathrm{rhTSH}+$ brief withdrawal group, compared with $38.6 \pm 4.0 \mu \mathrm{g} / 1$ in the withdrawal group, and $76.4 \pm 9.3 \mu \mathrm{g} / \mathrm{l}$ in 16 other patients receiving rhTSH for diagnostic purposes. The difference in urinary iodine concentrations between the rhTSH + brief withdrawal and rhTSH groups was significant $(P=0.019$, Student's $t$-test $)$. At 1-year follow-up, $81.2 \%$ of the rhTSH + brief withdrawal patients and $75.0 \%$ of the withdrawal patients had their remnants successfully ablated, defined by a negative rhTSH-stimulated dxWBS and undetectable thyroglobulin. Several factors complicate interpretation of the clinical relevance of this study, for example its small size and its lack of a control group receiving rhTSH for ablation without any withdrawal of $\mathrm{LT}_{4}$.

\section{rhTSH-aided treatment}

Curative or palliative radioiodine treatment is indicated when unresectable functioning tumour is present or suspected on the basis of increased thyroglobulin (Pacini et al. 1994, Reiners \& Farahati 1999, Pacini et al. 2001). An additional, experimental indication is in clinical trials of re-differentiation therapy with drugs such as retinoic acid (Jarzab et al. 2003). Pregnancy is the sole contraindication, and breast-feeding must be stopped when ${ }^{131}$ I therapy is planned.

The effect of radioiodine treatment correlates inversely with tumour mass and extent, and younger age is predictive of a favourable response (Reiners \& Farahati 1999, Schlumberger \& Pacini 2003). Quantitative data on the efficacy of withdrawal-aided radioiodine treatment of metastatic disease are relatively limited (Robbins et al. 2000). However, according to published experience, complete responses are achieved in from about $33 \%$ to $50 \%$ of patients with distant metastases, but may take up to 5 years of repeated treatments in about $33 \%$ of cases (Schlumberger \& Pacini 2003). Criteria for partial response vary between medical centres, but include (all without lesion growth at non-responding sites or appearance of new lesions): decreases in tumour volume clinically or by non- ${ }^{131}$ I WBS imaging modalities in tandem with decreases in ${ }^{131}$ I-WBS uptake; declines in serum thyroglobulin concentrations; improvement in performance status.

In publications to date, rhTSH has been used for a variety of reasons (Table 2) to aid radioiodine treatment in a total of 217 patients, aged 14 to 87 years (108 female, 90 male, 18 sex unreported or not clearly reported; histology: papillary in 69, follicular in 64 , Hürthle cell in 1, unreported or not clearly reported in 83) (Chiu et al. 1997, Adler et al. 1998, Rudavsky \& Freeman 1998, Colleran \& Burge 1999, Perros 1999, Masiukiewicz et al. 1999, Vargas et al. 1999, Jarzab et al. 2000a,b, 2003, Lippi et al. 2000, Mariani et al. 2000, Mazzaferri \& Kloos 2000, Robbins et al. 2000, Rotman-Pikielny et al. 2000, Aslam \& Daly 2001, Checrallah et al. 2001, McDougall \& Weigel 2001, Pellegritti et al. 2001, Berg et al. 2002, Müller et al. 2002, Robeson et al. 2002, Goffman et al. 2003, Gómez Camarero et al. 2003, de Keizer et al. 2003, Menzel et al. 2003, Driedger \& Kotowycz 2004, Kovatcheva et al. 2004, Taïeb et al. 2004). The published experience has encompassed at least 266 courses of rhTSH-aided radioiodine treatment, with 
Table 2 Published indication for use of $\mathrm{rTSH}$ in radioiodine therapy

\begin{tabular}{|c|c|}
\hline Indication & References \\
\hline $\begin{array}{l}\text { Insufficient or unusually slow } \\
\text { endogenous TSH production } \\
\text { after THST withdrawal as a } \\
\text { result of: } \\
\text { - Long-term THST } \\
\text { - Large thyroid remnant and/or } \\
\text { functioning metastases } \\
\text { - Glucocorticoid therapy } \\
\text { - Radiation-induced thyroiditis } \\
\text { - Pituitary or hypothalamic } \\
\text { disorders or damage } \\
\text { from radiotherapy of } \\
\text { brain metastases }\end{array}$ & $\begin{array}{l}\text { Adler et al. } 1998 \\
\text { Colleran \& Burge } 1999 \\
\text { Masiukiewicz et al. } 1999 \\
\text { Vargas et al. } 1999 \\
\text { Luster et al. } 2000 \text { b } \\
\text { Roman-Pikielny et al. } 2000 \\
\text { Checrallah et al. } 2001 \\
\text { Pellegritti et al. } 2001 \\
\text { Kovatcheva et al. } 2004\end{array}$ \\
\hline $\begin{array}{l}\text { Risk of progressive disease or } \\
\text { potentiation of tumour } \\
\text { compression symptoms with } \\
\text { prolonged exposure to } \\
\text { increased TSH, especially } \\
\text { in patients with: } \\
\text { - Bone metastases } \\
\text { - Lung metastases } \\
\text { - Lymph node metastases } \\
\text { - Brain or spinal cord } \\
\text { metastases }\end{array}$ & $\begin{array}{l}\text { Chiu et al. } 1997 \\
\text { Adler et al. } 1998 \\
\text { Aslam \& Daly et al. } 2001 \\
\text { Rudavsky \& Freeman } 1998 \\
\text { Luster et al. } 2000 \text { a } \\
\text { Robbins et al. } 2000 \\
\text { Berg et al. } 2002 \\
\text { Müller et al. } 2002 \\
\text { Jarzab et al. } 2003 \\
\text { Menzel et al. } 2003\end{array}$ \\
\hline $\begin{array}{l}\text { Risk of life-threatening or } \\
\text { debilitating } \\
\text { exacerbation or appearance } \\
\text { of concomitant illness: } \\
\text { - Ischaemic heart disease } \\
\text { - Renal insufficiency } \\
\text { - Hypoxia and/or dyspnoea } \\
\text { - Ischaemic brain disease } \\
\text { - Depression and/or } \\
\text { - Ssychological instability } \\
\text { - Gerious gastritis } \\
\text { - Seneral weakness } \\
\text { - Seveadache }\end{array}$ & $\begin{array}{l}\text { Rudavsky \& Freeman } 1998 \\
\text { Perros } 1999 \\
\text { Luster et al. } 2000 \\
\text { Mazzaferri \& Kloos } 2000 \\
\text { Pellegritti et al. } 2001 \\
\text { Berg et al. } 2002 \\
\text { Goffman et al. } 2003 \\
\text { Menzel et al. } 2003 \\
\text { Kovatcheva et al. } 2004 \\
\text { Taïeb et al. } 2004\end{array}$ \\
\hline $\begin{array}{l}\text { Risk of aggravation, by THST } \\
\text { withdrawal, of hyperlipidaemia } \\
\text { caused by clinical trial } \\
\text { of retinoic acid } \\
\text { re-differentiation therapy }\end{array}$ & Jarzab et al. 2003 \\
\hline $\begin{array}{l}\text { In patients needing very frequent } \\
\text { treatment, avoidance of } \\
\text { quality-of-life impairment of } \\
\text { nearly unremitting } \\
\text { hypothyroidism } \\
\text { secondary to withdrawals }\end{array}$ & Driedger \& Kotowycz 2004 \\
\hline $\begin{array}{l}\text { Patient refusal of THST } \\
\text { withdrawal }\end{array}$ & $\begin{array}{l}\text { Mazzaferri \& Kloos } 2000 \\
\text { Jarzab et al. } 2003\end{array}$ \\
\hline
\end{tabular}

THST, thyroid suppressive therapy; TSH, thyroid-stimulating hormone. up to six courses given per patient (Driedger \& Kotowycz 2004). Individual ${ }^{131}$ I activities ranged from 1000 to $19055 \mathrm{MBq}$.

The majority of patients were treated under the manufacturer's compassionate use programme. Hence they comprised individuals with bulky, widespread, late- or end-stage cancer, many of whom were elderly: $75 \%(113 / 150)$ of patients in whom disease status was reported had metastases and at least 39\% (59/150) were aged at least 65 years. More than $80 \%$ of published patients belonged to seven series of $8-54$ consecutive patients each or to a 64-patient dosimetric report; the balance appeared in case reports.

rhTSH-aided therapy appeared to promote the uptake of radioiodine by tumour tissue in nearly all patients with functioning lesions. One hundred and three $(75 \%)$ of 138 patients for whom post-therapy WBS results were published exhibited radioiodine uptake; among those lacking uptake, 19 represented non-responders to a trial of re-differentiation treatment; in four, the negative rhTSH-aided post-therapy WBS confirmed a suspected complete response to prior withdrawal-aided treatment or confirmed suspected disease-free status; in three, metastases apparently lost avidity for iodine because of disease progression; two had small pulmonary metastases that were nonfunctional on a prior or subsequent withdrawal-aided post-therapy scan; one had iodine excess from recent administration of a computed tomography contrast medium; and no explanation was published in the case of four others. Two of the patients lacking therapeutic radioiodine uptake after rhTSH administration, and an additional patient who lost rhTSH-aided therapeutic radioiodine uptake after five treatments, did demonstrate uptake after later withdrawal-aided treatment. The authors reporting two of these cases (Driedger \& Kotowycz 2004) speculated that their observations might be explained by disparities in the ability of some individuals' TSH receptors to take up recombinant and endogenous $\mathrm{TSH}$, which differ in sialylation.

Analysis of published outcomes of rhTSH-aided treatment (Table 3) shows that 74 of 115 patients $(65 \%)$ for whom this parameter was reported derived clinical benefit from this modality - that is, complete or partial remission or disease stabilization. There were only a single confirmed complete remission and one other possible complete response (in a patient who may have had only tumour remnant to begin with), but 41 partial responses, for an objective response rate of $38 \%$ ( $2 \%$ complete response rate plus $36 \%$ partial response rate). In addition, 31 patients $(27 \%)$ had disease stabilization. In this sometimes late- or end-stage 


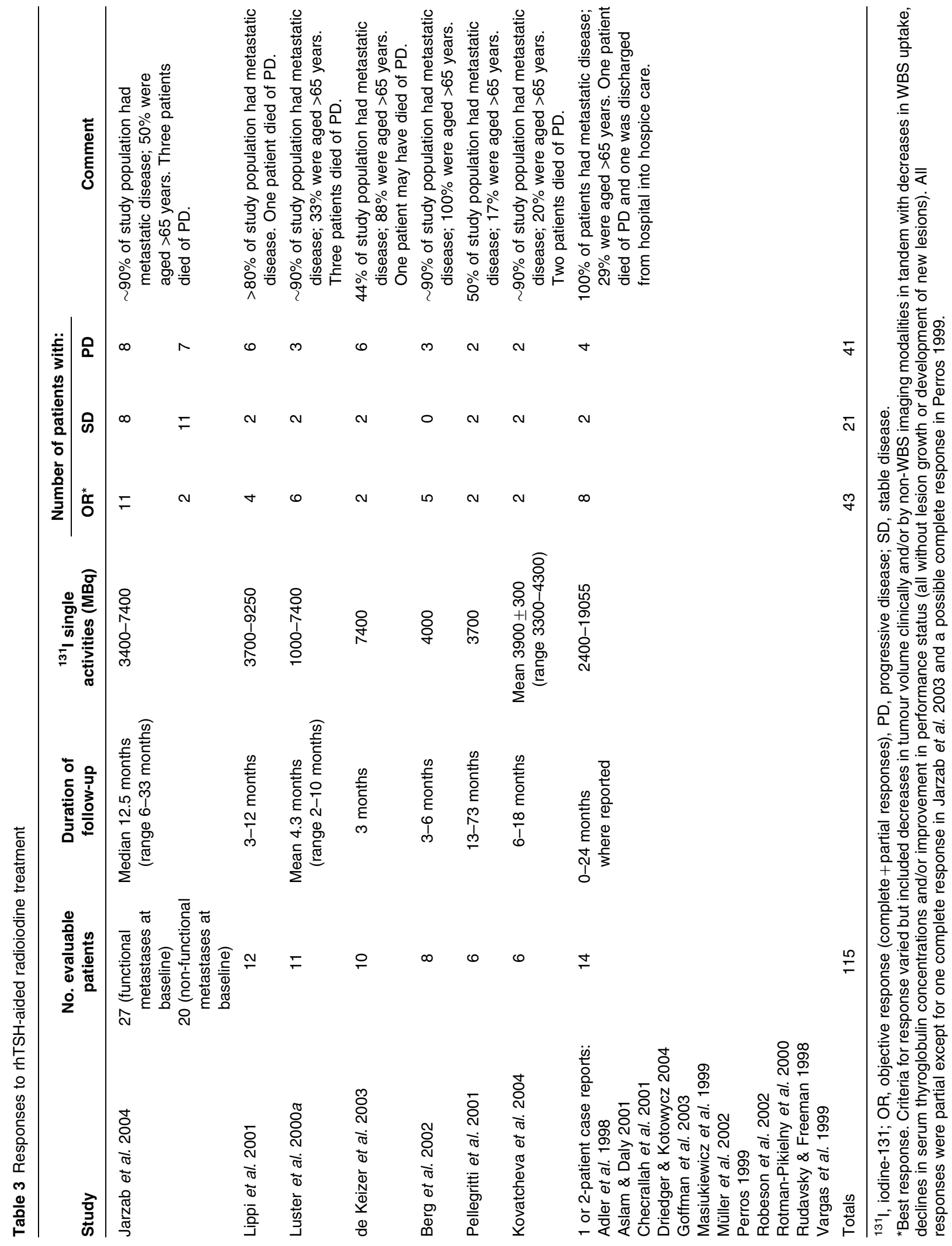


population, 9 non-responders died of apparent or possible progressive disease 40 days to 22 months after the first (and in most cases, only) rhTSH treatment. Another patient with a partial response of decreased periorbital oedema died 2 months after treatment, and a second patient with a partial response including good quality of life died at about 3 years of follow-up. A further patient was discharged from hospital into hospice care.

When published results of rhTSH-aided treatment are being evaluated, data must be interpreted cautiously, because standardized response criteria were used in only about $50 \%$ of the patients, and many papers did not give data for one or more parameters such as follow-up WBS, thyroglobulin measurement or clinical response. Moreover, randomized studies have not been published and, indeed, are unlikely to be performed, because of the relative rarity and great heterogeneity of metastatic DTC and the challenging ethical issues in this setting (Sherman 2003). The dearth of randomized studies, of course, increases the possibility of selection biases affecting reported results. However, any bias might lead to an understatement of efficacy, given the advanced disease stage and associated grim prognosis - exemplified by the 10 -year survival rate in the literature of approximately $11 \%$ for patients with several metastatic sites - of most of the published patient population (Reiners \& Farahati 1999, Schlumberger \& Pacini 2003). Despite the limitations of the published experience, there undoubtedly have been some patients in whom rhTSH-aided treatment achieved important clinical palliation such as restoration of ambulation, ability to work and socialize, or both, and diminution or resolution of bone pain (Adler et al. 1998, Rudavsky \& Freeman 1998, Robbins et al. 2002, Berg et al. 2002, Jarzab et al. 2003).

Two studies have revealed that the efficacy of rhTSH-aided treatment compares favourably with that of prior withdrawal-aided treatment. In a 54-patient, single-centre trial, Jarzab and co-workers (2003) made a qualitative comparison between post-therapy WBS after rhTSH and post-therapy scans obtained after the most recent withdrawal of THST. Two experienced clinicians evaluated the location and number of foci of uptake, with scans considered concordant if all visible foci in one scan were also present in the other. The possible impact of disease regression or progression on changes between scans was assessed in the light of clinical, laboratory and other radiological findings. Among 27 evaluable patients with functional metastases at baseline, median time between scans was 6 months (range 3-12 months), 18 (67\%) scan pairs were concordant, $4(15 \%)$ were discordant in favour of rhTSH, and $5(19 \%)$ were discordant in favour of THST withdrawal. Among 23 evaluable patients with non-functional metastases at baseline, 19 (83\%) scan pairs were concordant, and $4(17 \%)$ were discordant in favour of rhTSH. All discordant scans appeared to be explicable on clinical grounds. The scans discordant in favour of rhTSH were attributed to disease progression causing additional foci of uptake or to success of redifferentiation therapy with retinoic acid in restoring uptake in the rhTSH-aided scan compared with the withdrawal-aided scan. The scans discordant in favour of withdrawal were explained by tumour de-differentiation or by complete response to the most recent withdrawal-aided treatment.

In an earlier study, Lippi et al. (2001) had performed a retrospective comparison of rhTSH-aided and withdrawal-aided post-therapy WBS, using methodology similar that of Jarzab and co-workers (2003). They found concordance in six of nine evaluable pairs of scans, and additional sites of uptake in three pairs of rhTSH-aided scans. The latter finding was attributable to tumour progression between scans.

Jarzab and colleagues (2003) also compared the clinical and biochemical response to one to four courses of rhTSH-aided therapy with those to two to eight previous courses of withdrawal-aided therapy in 44 evaluable patients. They used standard criteria of objective response, disease stabilization and progressive disease. Twenty-three patients $(52 \%)$ had similar responses to the two modalities, $12(27 \%)$ had a superior response to rhTSH-aided treatment, 2 others $(5 \%)$ had a superior response to rhTSH-aided treatment, attributed to response to retinoic acid redifferentiation therapy, and 7 patients $(16 \%)$ had a superior response to withdrawal-aided treatment.

\section{Immediate biochemical effects of rhTSH}

In the 11 largest studies of rhTSH-aided therapy published to date (Lippi et al. 2001, Luster et al. 2000a, Mariani et al. 2000, Pellegritti et al. 2001, Berg et al. 2002, Robbins et al. 2002, Barbaro et al. 2003, Jarzab et al. 2003, de Keizer et al. 2003, Pacini et al. 2002, Kovatcheva et al. 2004), peak serum TSH concentrations after the administration of rhTSH ranged from 42 to $400 \mu \mathrm{U} / \mathrm{ml}$ in euthyroid patients and from 124 to $582 \mu \mathrm{U} / \mathrm{ml}$ in hypothyroid patients. One study observed that serum TSH generally remained increased $48 \mathrm{~h}$ beyond its peak (Lippi et al. 2000). This agrees with the observations of others that the standard twodose rhTSH regimen results in 3-4 days of increased 
serum TSH concentration, compared with 6-10 weeks after withdrawal of THST (Robbins et al. 2001).

Limited reports show generally minimal effect of the administration of rhTSH on serum free tri-iodothyronine and free $\mathrm{LT}_{4}$ concentrations in patients with DTC and total thyroidectomy (Luster et al. 2000a, Jarzab et al. 2003). Administration of rhTSH stimulated an increase in serum thyroglobulin concentrations in at least $67 \%$ of patients for whom data were reported.

\section{Safety of rhTSH}

Despite the frequently late-stage, elderly or frail nature of the 393 patients for whom data have been published, rhTSH-aided therapy generally was well tolerated, with most patients experiencing no, or only minor and transient, unwanted effects. The adverse events profile generally has been similar to that observed in the diagnostic phase III studies (Ladenson et al. 1997, Haugen et al. 1999), which included few patients with metastatic disease. However, as in the case of withdrawal of THST, an important safety consideration in relation to the administration of rhTSH involves potential TSH stimulation of thyroid expansion, with ensuing compression of key anatomical structures and neurological, respiratory or other clinical complications. This possibility warrants special attention in patients with known or suspected central nervous system or spinal metastases. It also warrants special attention in patients with bulky neck lesions or tumour remnants, or both, especially if they have poor lung reserve as a result of pulmonary fibrosis from having received high cumulative activities of prior radioiodine, or other causes (Goffman et al. 2003).

In their 54-patient study, for example, Jarzab et al. (2003) reported mild extremity paraesthesia in two of 21 rhTSH-aided courses given to patients with spinal and brain metastases. They also reported radiologically confirmed pathological spine fracture accompanied by paraparesis the night after the administration of radioiodine, in a 53-year-old woman with a large vertebral metastasis. In addition, neck tumour oedema developed, starting on the second day of application of rhTSH, in three of 20 patients with massive neck infiltrates; the oedema was accompanied by a choking sensation in two of the patients, and by dyspnoea in the other. A half dozen or so similar cases have been reported elsewhere (Vargas et al. 1999, Robbins et al. 2000, Braga et al. 2001, Berg et al. 2002, Goffman et al. 2003).

Transient, moderate-to-severe exacerbation of bone pain in patients with bone metastases also has been observed after the administration of rhTSH in three studies (Lippi et al. 2001, Berg et al. 2002, Jarzab et al. 2003). Such exacerbation occurred in $25 \%(8 / 32)$ of courses given to patients with bone metastases in the largest of these studies (Jarzab et al. 2003). Of interest, in most cases, patients stated that the increased bone pain was shorter-lived, milder, or both, after the administration of rhTSH than under prior withdrawal of THST, and in no case was it said to be longer-lived or more severe.

Three points should be noted about tumour enlargement after the administration of rhTSH. Firstly, its rapid onset, its response to glucocorticoid administration and the radiological findings of peritumoural oedema or, less commonly, haemorrhage, in the published cases, strongly suggest that the enlargement is attributable to tumour swelling rather than to growth (Vargas et al. 1999, Robbins et al. 2000, Braga et al. 2001, Berg et al. 2002, Jarzab et al. 2003). However, there may be rare instances in which stimulation of tumour growth by rhTSH cannot be ruled out (Jarzab et al. 2003). Secondly, rhTSH product labelling now recommends glucocorticoid premedication of, and caution with, patients with known or suspected lesions in confined spaces, as is recommended for patients subjected to withdrawal of THST. Thirdly, in studies to date, premedication with dexamethasone, prednisone or hydrocortisone, or combinations thereof, has avoided complications of tumour swelling in a number of high-risk patients, but not in all individuals (Luster et al. 2000a, Pellegritti et al. 2001, Berg et al. 2002). Meticulous clinical attention should be the rule when patients with known or suspected lesions in confined spaces are exposed to increases in TSH, whether withdrawal- or rhTSHstimulated.

Among the 394 patients described in the literature on rhTSH-aided therapy, a single case of clinical thyrotoxicosis, in which cardiac symptoms were easily relieved by $\beta$-blockers, has been reported in an individual with massive functional skeletal and softtissues masses (Jarzab et al. 2003). One case also has been reported of a patient who had pneumonia after rhTSH-aided treatment; the investigators did not state whether the pneumonia had any relationship to the intervention in this desperately ill patient (Rudavsky \& Freeman 1998).

\section{${ }^{131}$ I dosimetry under rhTSH stimulation}

The selective avidity of thyroid tissue for radioiodine and the short range of ${ }^{131} \mathrm{I} \beta$-radiation mean that doses of radiation delivered to extrathyroid tissues are about 
$1 / 1000-1 / 10000$ less than those delivered to thyroid tissue. Therefore in many cases, standard or empirical activities of ${ }^{131}$ I may be used for radioiodine ablation or treatment. However, pre-therapeutic measurement of whole-blood, whole-body, remnant or lesion kinetics of radioactivity in an individual after administration of a tracer activity of ${ }^{131} \mathrm{I}$ is sometimes used to 'customize' the activity to be used for a given therapeutic procedure.

The objective of whole-blood and whole-body dosimetry is to determine the maximum radioiodine activity that can be given in a procedure without serious risk of bone marrow depression or pulmonary fibrosis. Traditionally, a dose of $2 \mathrm{~Gy}$ of radiation to the blood (a surrogate for bone marrow) has been considered the safe limit to minimize the risk of bone marrow depression. An activity of $3 \mathrm{GBq}$ in the lung at $24 \mathrm{~h}$ has been considered the safe limit to avoid pulmonary fibrosis in patients with extensive lung involvement (Benua et al. 1962, Leeper 1973).

The objective of remnant or lesion dosimetry is to determine the radioiodine activity that delivers the recommended minimum dose of radiation to ablate the thyroid remnant or to treat metastatic disease. The doses are traditionally considered to be 300 and $80 \mathrm{~Gy}$ respectively (Maxon et al. 1992). In contrast to these pre-therapeutic dosimetric procedures, the radiation dose delivered by the ${ }^{131} \mathrm{I}$ therapeutic activity itself to the thyroid remnant or to lesions also may be measured after the therapy, to attempt to correlate this dose with clinical results.

In practice, patient-specific dosimetry has several limitations: estimations of the volume of tissue concentrating ${ }^{131}$ I may be imprecise, for example when micrometastases are too small for visualization; uptake can be heterogeneous, even within a particular lesion; and biological half-lives can vary according to the individual, lesion or time of measurement (Schlumberger \& Pacini 2003, Sgouros et al. 2004). In addition, poor physical condition may preclude an additional administration of ${ }^{131} \mathrm{I}$ (i.e. of a test activity) in some candidates for radioiodine therapy (Luster et al. 2000a). Furthermore, with rhTSH-aided therapy, measurement of a test activity would entail the cost of additional injections of rhTSH required to replicate the conditions of the actual therapy.

Nonetheless, some clinicians have advocated dosimetric studies before use of rhTSH-aided therapy, because experience of ${ }^{131} \mathrm{I}$ dosing gained in relation to THST withdrawal may not be wholly relevant when the patient is euthyroid (Mazzaferri \& Kloos 2000). Initial reports in the diagnostic setting, presumably from patients with minimal thyroid remnant or tumour, suggested that renal clearance of radioiodine generally was approximately $50 \%$ more rapid in the euthyroid than in the hypothyroid state (Park et al. 1996, Ladenson et al. 1997). More recently, a threecentre pilot German-American dosimetry study comparing biokinetics of diagnostic radioiodine administration after rhTSH administration and THST withdrawal (Luster et al. 2003) found that clearance of radioactivity from the blood was faster after the administration of rhTSH in all nine patients studied; the mean effective half-life of radioactivity after the standard course of two injections of $0.9 \mathrm{mg}$ rhTSH was $0.75 \pm 0.07$ times that after withdrawal. This study involved low-risk patients without evidence of disease after complete thyroidectomy, who were scheduled to receive remnant ablation after completion of the dosimetric study. All patients received $74 \mathrm{MBq}{ }^{131} \mathrm{I}$ test activity under THST after stimulation by two-day $(n=4)$ or three-day courses $(n=5)$ of rhTSH and then 4-6 weeks later under hypothyroid conditions $(n=9)$ after withdrawal of THST.

In the treatment setting, Robbins et al. (2000) found, in four dosimetric studies performed in a patient undergoing rhTSH-aided treatment, that whole-body radioiodine clearance was more rapid but, surprisingly, blood clearance was consistently less rapid in the euthyroid state than in the hypothyroid state (Robbins et al. 2000). Menzel et al. (2003) found that, despite considerable overlap in values between the groups, the mean effective whole-body half-life of radioiodine was significantly lower in consecutive patients receiving rhTSH stimulation than in other consecutive patients given withdrawal stimulation: $0.43 \pm 0.11$ days $(n=64)$ compared with $0.54 \pm 0.11$ days $(n=163)(P<0.001$, unpaired $t$-test). The significant difference persisted in subgroup analyses designed to factor-out possible effects of tumour burden and thyroid tissue volume.

In contrast, a recent report by de Keizer et al. (2003) on 16 evaluable patients given 19 courses of rhTSHaided treatment with a radioiodine activity of $7400 \mathrm{MBq}$ noted median biological and effective halflives of radioiodine of 4.1 days (range 0.6-34.7 days) and 2.7 days (range 0.5-6.5 days) respectively, in tumour. These half-lives were comparable to data obtained after withdrawal-aided therapy, suggesting similar iodine kinetics in thyroid cancer tissue after both forms of TSH stimulation.

In theory, a more rapid clearance of radioiodine in euthyroidism might result in delivery of a lower dose to the thyroid remnant or tumour after administration of rhTSH than after withdrawal of THST. The lower dose presumably would be attributable at least in part to decreased ${ }^{131}$ I re-uptake by thyroid tissue of previously 
secreted radioiodine, as a result of the reduced radioiodine pool in the bloodstream over time. Decreased radioiodine availability for re-uptake would be expected to be more relevant in treatment than in ablation, because of the diminished uptake and organification of radioiodine in metastases compared with that in healthy thyroid tissue (Schlesinger et al. 1989).

The recent University of Pisa ablation study (Pacini et al. 2002) found that the rhTSH group had significantly lower mean 24-hour thyroid uptake of a test activity of radioiodine than did the THST withdrawal or THST withdrawal+rhTSH groups: $2.5 \pm 4.3 \%$ (range $0.1-32 \%$ ) compared with $5.8 \pm 5.7 \%$ (range $0.2-21 \%$ ) and $5.4 \% \pm 5.7 \%$ (range $0.2-26 \%$ ) respectively $(P<0.0001)$. The Pisa investigators found that the mean initial dose rate, a value proportional to the 24 hour ${ }^{131} \mathrm{I}$ uptake divided by the remnant mass (determined by ultrasound), also was significantly lower for the rhTSH group than for the THST withdrawal or THST withdrawal + rhTSH groups: $10.7 \pm 12.6 \mathrm{~Gy} / \mathrm{h}$ compared with $27.1 \pm 42.5 \mathrm{~Gy} / \mathrm{h} \quad(P=0.01)$ and $48.5 \pm 43.0 \mathrm{~Gy} / \mathrm{h}(P<0.001)$ respectively. However, in that study, therapeutic radioiodine was administered 24 or $48 \mathrm{~h}$ later (rhTSH and withdrawal + rhTSH respectively) than in other ablation or treatment series. Furthermore, the method used to measure the dose delivered to tumour remnant did not give the cumulative absorbed dose, and is validated by only one previous study (Samuel \& Rajashekharrao 1994).

In contrast to the observations in the Pisa study, the German-American dosimetry study found that the remnant dose was greater after rhTSH than after withdrawal in eight of nine patients; overall, residence time was $5.7 \pm 6.3$ times longer after rhTSH. However, the investigators noted that these results may have been influenced by a sequencing effect of 'stunning' of the thyroid remnant by the first, rhTSH-aided test dose. In the treatment setting, de Keizer et al. (2003) found that the dose absorbed by the tumour was a median 26.3 Gy (range 1.3-368.4 Gy), and exceeded $80 \mathrm{~Gy}$ in only five of 25 tumours.

In theory, delivery of a lower dose to remnant or lesions in euthyroidism might affect the efficacy of rhTSH-aided therapy. However, in studies reported to date, the correlation between dose absorbed by the remnant or tumour and the clinical or biochemical response has been unclear. In the University of Pisa ablation study, although ablation was successful in all patients in whom the initial dose rate was greater than $50 \mathrm{~Gy} / \mathrm{h}$, the initial dose rate overlapped extensively between those in whom ablation was and was not achieved. In the treatment study performed by de Keizer et al. (2003), several patients with tumour absorbed doses below the 80 Gy threshold nonetheless exhibited a partial thyroglobulin response or shrinkage of several metastatic lesions confirmed by chest X-ray.

On the basis of the dosimetric and clinical results of their ablation study, the University of Pisa investigators speculated that increased radioiodine activities could improve the efficacy of rhTSH-aided procedures (Pacini et al. 2002). In their 12-patient study of rhTSHaided treatment (Lippi et al. 2001), the Pisa team empirically increased their treatment activity from $52-74 \mathrm{MBq} / \mathrm{kg}$ of body weight (their standard range under THST withdrawal), to $100-111 \mathrm{MBq} / \mathrm{kg}$, with some successful clinical outcomes and no apparent radioiodine toxicity. However, other reported studies (e.g. Luster et al. 2000a, Robbins et al. 2001, 2002, Berg et al. 2002, Jarzab et al. 2003) seem to have administered customary institutional activities of ${ }^{131} \mathrm{I}$ in conditions of THST withdrawal, with no apparent diminution of ablation or treatment efficacy.

Were an increased therapeutic activity necessary with the use of rhTSH, the possibility of adverse effects of the larger activities on the bone marrow or lungs presumably would be mitigated by the faster wholebody radioiodine clearance and resultant decreased exposure of extrathyroid tissues to radiation in euthyroid patients. Were an increased therapeutic activity unnecessary, the faster clearance associated with the administration of rhTSH might decrease the whole-body and whole-blood retention of radioiodine, with attendant safety benefits, decreased hospital stays, or both. In fact, in one 11-patient study of rhTSHaided therapy that successfully used activities similar to those administered after withdrawal, the investigators reported an anecdotal impression that patients generally were able to leave the radioprotection ward 1-2 days sooner after rhTSH-aided than after past withdrawal-aided procedures (Berg et al. 2002).

de Keizer et al. (2003) speculated that the lower doses of radiation delivered to the tumour in their study with rhTSH, compared with those associated with withdrawal of THST, might be attributable to interference with radioiodine uptake by iodine derived from the continuing thyroid hormone treatment in patients given rhTSH. As noted earlier, in a small study, Barbaro et al. (2003) found that rhTSH-aided ablation with $1110 \mathrm{MBq}$ radioiodine and a 4-day 'mini-withdrawal' around the time of administration of radioiodine resulted in numerically greater success rates than those attained with conventional THST withdrawal; however, in the absence of a study arm in which rhTSH was given without a 'mini-withdrawal,' the 7-day half-life of $\mathrm{LT}_{4}$ calls into question whether the 'mini-withdrawal' really had any impact. 
In summary, to date, dosimetric findings have been published in widely varying levels of detail in 259 patients given rhTSH-aided therapy (Luster et al. 2000b, 2003, Mazzaferri \& Kloos 2000, Robbins et al. 2000, 2001 2002, Rotman-Pikielny et al. 2000, Pacini et al. 2002, de Keizer et al. 2003, Menzel et al. 2003). Despite the relatively large number of publications and population of patients reported, questions of methodology, bias and clinical relevance surround the data accrued, so that knowledge of the kinetics of radioiodine after the administration of rhTSH and their efficacy and safety impact must still be considered as preliminary, and further investigation desirable.

\section{rhTSH-aided ablation and treatment: current status, future directions}

Radioiodine ablation of thyroid remnants would seem to be a logical setting for the administration of rhTSH, because of the desirability of avoiding hypothyroidism in the generally younger, healthier and more active population of patients undergoing this procedure. In such patients, economic savings from preserving the ability to work and, in some instances, from obviating the need to return for radioiodine ablation weeks or months after thyroidectomy, should offset the cost of rhTSH in some cases at least (M Luster, R Felbinger, $M$ Dietlein \& C Reiners). Published experience to date has shown the safety and, especially when radioiodine activities of at least $4000 \mathrm{MBq}$ are used, the efficacy of rhTSH in aiding ablation (Robbins et al. 2001, 2002, Berg et al. 2002, Pacini et al. 2002, Barbaro et al. 2003, Kovatcheva et al. 2004). These benefits may be further established when results are reported from a recently completed randomized pilot clinical study comparing rhTSH and THST withdrawal as adjuncts to ablation. This study at eight locations in five countries involved a total of approximately 60 adults with well differentiated papillary or follicular thyroid carcinoma and used a fixed ${ }^{131}$ I activity of $3700 \mathrm{MBq}$.

Regarding rhTSH as an aid to treatment, the published international experience in 217 patients, most with advanced disease, suggests that rhTSH safely and effectively stimulates the uptake of radioiodine in local and metastatic lesions of well differentiated thyroid cancer, and that it may achieve clinical benefit in a substantial percentage of patients, even those in whom the cancer is late-stage. The results also suggest that rhTSH-aided treatment may have an efficacy at least equivalent to that of withdrawal-aided treatment, even though in most cases, the ${ }^{131}$ I activities given in the rhTSH-aided treatment were not adjusted to compensate for the faster clearance of radioiodine in the euthyroid state. rhTSH stimulation may become the modality of choice in most, if not all, the categories of patients listed in Table 1, and certainly merits additional investigation, preferably in randomized studies, including in younger patients with less advanced disease.

\section{Acknowledgements}

The authors thank Robert $\mathbf{J}$ Marlowe for editorial assistance on this paper, provided under an unrestricted grant by Genzyme Europe BV, Naarden, The Netherlands.

\section{References}

Adler ML, Macapinlac HA \& Robbins RJ 1998 Radioiodine treatment of thyroid cancer with the aid of recombinant human thyrotropin. Endocrine Practice 4 282-286.

Aslam SN \& Daly RG 2001 Use of recombinant human thyrotropin in a complicated case of metastatic papillary thyroid carcinoma. Endocrine Practice 7 99-101.

Barbaro D, Boni G, Meucci G, Simi U, Lapi P, Orsini P, Pasquini C, Piazza F, Caciagli M \& Mariani G 2003 Radioiodine treatment with $30 \mathrm{mCi}$ after recombinant human thyrotropin stimulation in thyroid cancer: effectiveness for postsurgical remnants ablation and possible role of iodine content in L-thyroxine in the outcome of ablation. Journal of Clinical Endocrinology and Metabolism 88 4110-4115.

Benua RS, Cicale NR, Sonenberg M \& Rawson RW 1962 Relation of radioiodine dosimetry to results and complications in treatment of metastatic thyroid cancer. American Journal of Roentgenology 87 171-182.

Berg G, Lindstedt G, Suurküla M \& Jansson S 2002 Radioiodine ablation and therapy in differentiated thyroid cancer under stimulation with recombinant human thyroid-stimulating hormone (rhTSH). Journal of Endocrinological Investigation 25 44-52.

Braga M, Ringel MD \& Cooper DS 2001 Sudden enlargement of local recurrent thyroid tumor after recombinant human TSH administration [clinical case seminar]. Journal of Clinical Endocrinology and Metabolism 86 5148-5151.

Brans B, Gemmel F, De Winter O, Fiers T, De Roose J, Vermeesch H, Rubens R, Kaufman JM \& Dierckx RA 2001 Recombinant human thyrotropin (rhTSH): a new aid in the diagnosis and treatment of thyroid carcinoma with radioiodine. Acta Clinica Belgica 56 316-320.

Checrallah A, Medlej R, Saade C, Khayat G \& Halaby G 2001 Malignant struma ovarii: an unusual presentation [case history]. Thyroid 11 889-892.

Chiu AC, Delpassand ES \& Sherman SI 1997 Prognosis and treatment of brain metastases in thyroid carcinoma. 
Journal of Clinical Endocrinology and Metabolism 82 3637-3642.

Colleran KM \& Burge MR 1999 Isolated thyrotropin deficiency secondary to primary empty sella in a patient with differentiated thyroid carcinoma: an indication for recombinant thyrotropin. Thyroid 9 1249-1252.

DeGroot LJ, Kaplan EL, Straus FH \& Shukla MS 1994 Does the method of management of papillary thyroid carcinoma make a difference in outcome? World Journal of Surgery 18 123-130.

Dow KH, Ferrell BR \& Anello C 1997 Quality-of-life changes in patients with thyroid cancer after withdrawal of thyroid hormone therapy. Thyroid 7 613-619.

Driedger AA \& Kotowycz N 2004 Two cases of thyroid carcinoma that were not stimulated by recombinant human thyrotropin [clinical case seminar]. Journal of Clinical Endocrinology and Metabolism 89 585-590.

Goffman T, Ioffe V, Tuttle M, Bowers JT \& Mason ME 2003 Near-lethal respiratory failure after recombinant human thyroid-stimulating hormone use in a patient with metastatic thyroid carcinoma [case history]. Thyroid $\mathbf{1 3}$ 827-830.

Gómez Camarero P, Martínez Brocca MA, Rodríguez Rodríguez JR, Navarro González E, Tirado Hospital JL, González Duarte D, Vásquez Albertino R \& Astorga Jiménez R 2003 La TSH humana recombinante en el seguimiento de pacientes con cáncer diferenciado de tiroides. Revista Española de Medicina Nuclear 22 295-305.

Haugen BR, Pacini F, Reiners C, Schlumberger M, Ladenson PW, Sherman SI, Cooper DS, Graham KE, Braverman LE, Skarulis MC, Davies TF, DeGroot LJ, Mazzaferri EL, Daniels GH, Ross DS, Luster M, Samuels MH, Becker DV, Maxon HR III, Cavalieri RR, Spencer CA, McEllin K, Weintraub BD \& Ridgway EC 1999 A comparison of recombinant human thyrotropin and thyroid hormone withdrawal for the detection of thyroid remnant or cancer. Journal of Clinical Endocrinology and Metabolism 84 3877-3885.

Jarzab B, Handkiewicz-Junak D \& Gawkowska-Suwinska M $2000 a$ Recombinant human TSH in the diagnosis and treatment of disseminated differentiated thyroid cancer. Nuclear Medicine Reviews of Central and Eastern Europe 3 83-88.

Jarzab B, Roskosz J, Gawkowska-Suwinska M, Turska M, Handkiewicz-Junak D, Puch Z, Wygoda Z \& Zajusz A 2000 b Recombinant human TSH for the treatment of differentiated thyroid cancer metastatic to the spine [short communication]. Nuclear Medicine Reviews of Central and Eastern Europe 3 157-160.

Jarzab B, Handkiewicz-Junak D, Roskosz J, Puch Z, Wygoda Z, Kukulska A, Jurecka-Lubiniecka B, HesseLazar K, Turska M \& Zajusz A 2003 Recombinant human TSH-aided radioiodine treatment of advanced differentiated thyroid cancer: single-center study of 54 patients. European Journal of Nuclear Medicine and Molecular Imaging 30 1077-1086. de Keizer B, Brans B, Hoekstra A, Zelissen PM, Koppeschaar HP, Lips CJ, Van Rijk PP, Dierckx RA \& De Klerk JM 2003 Tumour dosimetry and response in patients with metastatic differentiated thyroid cancer using recombinant human thyrotropin before radioiodine therapy. European Journal of Nuclear Medicine and Molecular Imaging 30 367-373.

Kovatcheva RD, Hadjieva TD, Kirilov GG \& Lozanov BS 2004 Recombinant human $\mathrm{TSH}$ in radioiodine treatment of differentiated thyroid cancer. Nuclear Medicine Review 7 13-19.

Ladenson PW, Braverman LE, Mazzaferri EL, BruckerDavis F, Cooper DS, Garber JR, Wondisford FE, Davies TF, DeGroot LJ, Daniels GH, Ross DS \& Weintraub BD 1997 Comparison of administration of recombinant human thyrotropin with withdrawal of thyroid hormone for radioactive iodine scanning in patients with thyroid carcinoma. New England Journal of Medicine 337 888-896.

Leeper RD 1973 The effect of 131 I therapy on survival of patients with metastatic papillary or follicular thyroid carcinoma. Journal of Clinical Endocrinology and Metabolism 36 1143-1152.

Lippi et al. 2000 [author to complete]

Lippi F, Capezzone M, Angelini F, Taddei D, Molinaro E, Pinchera A \& Pacini F 2001 Radioiodine treatment of differentiated thyroid cancer on L-thyroxine plus recombinant human TSH (rhTSH): initial single-center experience. European Journal of Endocrinology 144 5-11.

Löffler M, Weckesser M, Franzius C, Kies P \& Schober O 2003 Iodine excretion during stimulation with rhTSH in differentiated thyroid carcinoma. Nuklearmedizin $\mathbf{4 2}$ 240-243.

Luster M, Lassmann M, Haenscheid M, Michalowski U, Incerti C \& Reiners C $2000 a$ Use of recombinant human thyrotropin before radioiodine therapy in patients with advanced differentiated thyroid carcinoma. Journal of Clinical Endocrinology and Metabolism 85 3640-3645.

Luster M, Reinhardt W, Koerber C, Lassmann M, Haenscheid H, Michalowski U, Rendl J, Eising E, Mann $\mathrm{K} \&$ Reiners C 2000b The use of recombinant human TSH in a patient with metastatic follicular cancer and secondary hypothyroidism. Journal of Endocrinological Investigation 23 473-475.

Luster M, Sherman SI, Skarulis MC, Reynolds JR, Lassmann M, Hänscheid H \& Reiners C 2003 Comparison of radioiodine biokinetics following the administration of recombinant human thyroid stimulating hormone and after thyroid hormone withdrawal in thyroid carcinoma. European Journal of Nuclear Medicine and Molecular Imaging 30 1371-1377.

Mariani G, Ferdeghini M, Augeri C, Villa G, Taddei GZ, Scopinaro G, Boni G, Bodei L, Rabitti C, Molinari E \& Bianchi R 2000 Clinical experience with recombinant human thyrotropin (rhTSH) in the management of patients with differentiated thyroid cancer. Cancer Biotherapy and Radiopharmaceuticals 15 211-217. 
Masiukiewicz US, Nakchbandi IA, Stewart AF \& Inzucchi SE 1999 Papillary thyroid carcinoma metastatic to the pituitary gland. Thyroid 9 1023-1027.

Maxon HR, Englaro EE, Thomas SR, Hertzberg VS, Hinnefeld JD, Chen LS, Smith H, Cummings D \& Aden MD 1992 Radioiodine-131 therapy for well-differentiated thyroid cancer - a quantitative radiation dosimetric approach: outcome and validation in 85 patients. Journal of Nuclear Medicine 33 1132-1136.

Mazzaferri EL 1997 Thyroid remnant ${ }^{131}$ I ablation for papillary and follicular thyroid carcinoma. Thyroid 7 265-271.

Mazzaferri EL \& Kloos RT 2000 Using recombinant human $\mathrm{TSH}$ in the management of well-differentiated thyroid cancer: current strategies and future directions [review]. Thyroid 10 767-778.

McDougall IR \& Weigel RJ 2001 Recombinant human thyrotropin in the management of thyroid cancer. Current Opinion in Oncology 13 39-43.

Meier CA, Braverman LE, Ebner SA, Veronikis I, Daniel GH, Ross DS, Deraska DJ, Davies TF, Valentine M \& DeGroot LJ 1994 Diagnostic use of recombinant human thyrotropin in patients with thyroid carcinoma (Phase I/II Study). Journal of Clinical Endocrinology and Metabolism 78 188-196.

Menzel C, Kranert WT, Döbert N, Diehl M, Fietz T, Hamscho N, Berner U \& Grünwald F 2003 rhTSH stimulation before radioiodine therapy in thyroid cancer reduces the effective half-life of ${ }^{131}$ I. Journal of Nuclear Medicine 44 1065-1068.

Müller V, Bohuslavizki KH, Klutmann S \& Clausen M 2002 Value of recombinant human thyrotropin in high-dose radioiodine therapy: a case report. Journal of Nuclear Medicine Technology 30 185-188.

Pacini F, Cetani F, Miccoli P, Mancusi F, Ceccarelli C, Lippi F, Martino E \& Pinchera A 1994 Outcome of 309 patients with metastatic differentiated thyroid carcinoma treated with radioiodine. World Journal of Surgery 18 600-604.

Pacini F, Agate L, Elisei R, Capezzone M, Ceccarelli C, Lippi F, Molinaro E \& Pinchera A 2001 Outcome of differentiated thyroid cancer with detectable serum $\mathrm{Tg}$ and negative diagnostic ${ }^{131} \mathrm{I}$ whole body scan: comparison of patients treated with high ${ }^{131}$ I activities versus untreated patients. Journal of Clinical Endocrinology and Metabolism 86 4092-4097.

Pacini F, Molinaro E, Castagna MG, Lippi F, Ceccarelli C, Agate L, Elisei R \& Pinchera A 2002 Ablation of thyroid residues with $30 \mathrm{mCi} 131 \mathrm{I}$ : a comparison in thyroid cancer patients prepared with recombinant human TSH or thyroid hormone withdrawal. Journal of Clinical Endocrinology and Metabolism $\mathbf{8 7}$ 4063-4068.

Park S-G, Reynolds JC, Brucker-Davis F, Whatley M, McEllin K, Maxted D, Robbins J \& Weintraub BD 1996 Iodine kinetics during I-131 scanning in patients with thyroid cancer: comparison of studies with recombinant human TSH (rhTSH) vs. hypothyroidism. Journal of Nuclear Medicine 37 (Suppl) 15P, abstract 49.

Pellegritti G, Scollo C, Giuffrida D, Vigneri R, Squatrito S \& Pezzino V 2001 Usefulness of recombinant human thyrotropin in the radiometabolic treatment of selected patients with thyroid cancer. Thyroid 11 1025-1030.

Perros P 1999 Recombinant human thyroid-stimulating hormone (rhTSH) in the radioablation of welldifferentiated thyroid cancer: preliminary therapeutic experience. Journal of Endocrinological Investigation 22 (Suppl) 30-34.

Reiners C \& Farahati J 1999 131I therapy of thyroid cancer patients. Quarterly Journal of Nuclear Medicine $\mathbf{4 3}$ 324-335.

Robbins RJ, Voelker E, Wang W, Macapinlac HA \& Larson SM 2000 Compassionate use of recombinant human thyrotropin to facilitate radioiodine therapy: case report and review of the literature. Endocrine Practice 6 460-464.

Robbins RJ, Tuttle RM, Sonenberg M, Shaha A, Sharaf R, Robbins H, Fleisher M \& Larson SM 2001 Radioiodine ablation of thyroid remnants after preparation with recombinant human thyrotropin. Thyroid 11 865-869.

Robbins RJ, Larson SM, Sinha N, Shaha A, Divgi C, Pentlow KS, Ghossein R \& Tuttle RM 2002 A retrospective review of the effectiveness of recombinant human TSH as preparation for radioiodine thyroid remnant ablation [brief communication]. Journal of Nuclear Medicine 43 1482-1488.

Robeson WR, Ellwood JE, Margulies P \& Margouleff D 2002 Outcome and toxicity associated with maximum safe dose radioiodine treatment of metastatic thyroid cancer. Clinical Nuclear Medicine 27 556-566.

Rotman-Pikielny P, Reynolds JC, Barker WC, Yen PM, Skarulis MC \& Sarlis NJ 2000 Recombinant human thyrotropin for the diagnosis and treatment of a highly functional metastatic struma ovarii. Journal of Clinical Endocrinology and Metabolism 85 237-244.

Rudavsky AZ \& Freeman LM 1998 Treatment of scannegative, thyroglobulin-positive metastatic thyroid cancer using radioiodine ${ }^{131} \mathrm{I}$ and recombinant human thyroidstimulating hormone [clinical case seminar]. Journal of Clinical Endocrinology and Metabolism 82 11-14.

Samuel AM \& Rajashekharrao B 1994 Radioiodine therapy for well-differentiated thyroid cancer: a quantitative dosimetric evaluation for remnant thyroid ablation after surgery. Journal of Nuclear Medicine $\mathbf{3 5}$ 1944-1950.

Schlesinger T, Flower MA \& McCready VR 1989 Radiation dose assessments in radioiodine $\left({ }^{131} \mathrm{I}\right)$ therapy. 1 . The necessity for in vivo quantitation and dosimetry in the treatment of carcinoma of the thyroid. Radiotherapy and Oncology 14 35-41.

Schlumberger M \& Pacini F 2003 Thyroid tumors, edn 5, pp 3-317. Paris: Editions Nucléon.

Schlumberger M, Ricard M \& Pacini F 2000 Clinical use of recombinant TSH in thyroid cancer patients [invited review]. European Journal of Endocrinology 143 557-563. 
Sgouros G, Kolbert KS, Sheikh A, Pentlow KS, Mun EF, Barth A, Robbins RJ \& Larson SM 2004 Patient-specific dosimetry for ${ }^{131}$ I thyroid cancer therapy using ${ }^{124}$ I PET and 3-dimensional-internal dosimetry (3D-ID) software. Journal of Nuclear Medicine 45 1366-72.

Sherman SI 2003 Thyroid cancer. Lancet 361 501-511.

Taïeb D, Jacob T, Zotian E \& Mundler O 2004 Lack of efficacy of recombinant human thyrotropin versus thyroid hormone withdrawal for radioiodine therapy imaging in a patient with differentiated thyroid carcinoma lung metastases [case history]. Thyroid 14 465-467.

Vargas GE, Uy H, Bazan C, Guise TA \& Bruder JM 1999 Hemiplegia after thyrotropin alfa in a hypothyroid patient with thyroid carcinoma metastatic to the brain. Journal of Clinical Endocrinology and Metabolism 84 3867-3871. 